\title{
Percalços na História da Ciência: B. F. Skinner e a Aceitação Inicial da Análise Experimental do Comportamento entre as Décadas de 1930 e $1940^{1}$
}

\author{
Robson Nascimento da $\mathrm{Cruz}^{2}$ \\ Universidade Federal de Minas Gerais
}

\begin{abstract}
RESUMO - A elaboração inicial do conceito de condicionamento operante e do delineamento experimental de sujeito único define as bases do sistema explicativo skinneriano em meados de 1930. Todavia, essas formulações não foram imediatamente aceitas. Com o objetivo de compreender os motivos envolvidos nesse episódio da história inicial da Análise do Comportamento, discutimos três eventos históricos, quais sejam: a) as dificuldades enfrentadas por Skinner após o seu pós-doutorado; b) a recepção ao seu primeiro livro, The Behavior of Organisms; c) a disputa com outros modelos explicativos do comportamento. Uma história constituída por determinantes de natureza motivacional, institucional, emocional, econômica e pelas dificuldades de ir na contramão de tendências dominantes na Psicologia Experimental norte-americana é o que se conclui na presente investigação.
\end{abstract}

Palavras-Chaves: B. F. Skinner; Behaviorismo Radical; Análise do Comportamento; Análise Experimental do Comportamento; História da Psicologia;

\section{Mishaps in the history of science: B. F. Skinner and the initial reaction to the Experimental Analysis of Behavior between the 1930's and the 1940's}

\begin{abstract}
The initial draft of the concept of operant conditioning and of the single-subject experimental design defines the bases of Skinner's explanatory system. However, these formulations were not immediately welcomed. To enable a closer look on the history of formation of Behavior Analysis, three historical facts were highlighted: (a) the difficulties faced by Skinner at the end of his post-graduate studies; (b) the reaction to his first book, The Behavior of Organisms, and (c) the dispute with other explanatory behaviorial models. The conclusion of the present study is that the history of formation of Behavior Analysis is constituted by determinants of motivational, institutional, emotional and economic nature and by difficulties of going against the dominant methodological trends of North-American Experimental Psychology.
\end{abstract}

Keywords: B. F. Skinner; Radical Behaviorism; Behavior Analysis; Experimental Analysis of Behavior; History of Psychology;

Quando voltamos efetivamente nossos esforços para a compreensão da história da ciência, dificilmente podemos afirmar que a situação atual de uma disciplina científica seja produto de uma evolução linear constituída somente por uma série de eventos bem-sucedidos. No entanto, não é incomum que as tradicionais versões historiográficas da ciência descrevam o desenvolvimento da ciência dessa maneira. Embora possa parecer à primeira vista ingênuo descrever a história da ciência como um evento eminentemente progressista, para Kuhn (1962/2006) essa é uma estratégia que desempenha objetivo bastante específico: o sentido de participação em uma tradição científica vencedora. Ainda para Kuhn:

Por certo os cientistas não são o único grupo que tende a ver o passado de sua disciplina como um desenvolvimento linear em direção ao ponto de vista privilegiado do presente. A tentação de escrever a história passada a partir do presente é generalizada

1 Este artigo é parte da pesquisa de doutorado em andamento: "Uma História Social da Análise do Comportamento: da aceitação inicial à organização comunitária da ciência". O autor agradece os comentários realizados pela professora Carolina Laurenti da Universidade Estadual de Maringá, e pela mestranda Luciana Maria de Souza, do Departamento de Psicologia da Universidade Federal de Minas Gerais. Ainda assim, admite a responsabilidade integral por eventuais erros e omissões.

2 Endereço para correspondência: Rua Agenor Alves, 68, Bairro Nazaré, Belo Horizonte. Minas Gerais, MG CEP 31990-040. Email: robsonncruz@ig.com.br e perene. Mas os cientistas são mais afetados pela tentação de reescrever a história, em parte porque os resultados da pesquisa científica não revelam nenhuma dependência óbvia com relação ao contexto histórico da pesquisa e em parte porque, exceto durante as crises e as revoluções, a posição contemporânea do cientista parece muito segura. (Kuhn 1962/2006 p.178)

A desconsideração de que a história da ciência, assim como a história de vida de qualquer indivíduo, não é constituída apenas por uma série de episódios vitoriosos é um dos problemas desse tipo de interpretação. Ademais, a partir dessa perspectiva historiográfica, fracassos, decepções e dificuldades enfrentadas pelos cientistas deixam de ser considerados relevantes para compreensão da história de uma ciência. No máximo, são descritos como parte dos seus bastidores, sem relação direta com os rumos que uma ciência tomou e com sua situação atual.

O fato é que "É muito difícil, se não impossível, dar uma acurada explicação histórica de uma disciplina científica" (Fleck, 1935/1979, p.14). Mas, é considerando a relevância de investigar os inúmeros elementos envolvidos na história de uma ciência, que analisamos, neste artigo, um episódio histórico que expõe como algumas dificuldades de aceitação de uma nova abordagem científica constituem parte relevante da história da ciência. Para tanto, examinamos os primeiros percalços enfrentados pelo cientista do comportamento B. 
F. Skinner (1904-1990), entre a segunda metade da década de 1930 e início dos anos de 1940. Tal período corresponde à primeira década de trabalho desse psicólogo após a elaboração inicial de seu inovador método de pesquisa - o delineamento experimental de sujeito único e o esboço de sua principal formulação científica - o conceito de condicionamento operante.

As dificuldades em se adaptar a um ambiente acadêmico diverso ao experimentado entre os anos de 1928 e 1935 , durante seu doutorado e pós-doutorado na Universidade de Harvard, a recepção negativa de suas primeiras formulações sobre um novo sistema científico, e as disputas com outros psicólogos e suas teorias do comportamento foram os pontos tratados neste trabalho.

Uma história constituída por determinantes de natureza motivacional, emocional, institucional, econômica e pelas dificuldades de Skinner em ir na contramão de tendências metodológicas dominantes na Psicologia Experimental norte-americana é o que se conclui nesta investigação.

\section{Do reforço à punição: Skinner e as consequências da mudança de ambiente institucional em meados da década de 1930}

Após a elaboração inicial de seu sistema científico, em meados da década de 1930, Skinner, ao contrário do planejado, não se volta exclusivamente para pesquisas relacionadas à sua formulação inicial da noção de operante ${ }^{3}$, e o uso de seu método de pesquisa - o delineamento experimental de sujeito único - mesmo sendo essas as prioridades de seu "plano de campanha" a ser desenvolvido entre as décadas de 1930 e 1960 (Skinner, 1979). Esse desvio ocorre, primeiramente, por causa das dificuldades em conseguir seu primeiro emprego em uma universidade que lhe propiciasse condições semelhantes àquelas encontradas em Harvard nos anos de doutorado e pós-doutorado em 1935. Por conseguinte, houve dificuldade de alcançar uma posição acadêmica minimamente confortável até meados da década de 1940.

Assim, a situação profissional desfavorável em que Skinner se encontra após o término de sua última bolsa de pós-doutorado constitui o primeiro percalço no caminho para continuidade de suas pesquisas e para a disseminação de seu esboço inicial de uma nova ciência do comportamento. Porém, antes de tratarmos desse aspecto, recordamos que, nos anos anteriores, em Harvard, Skinner havia realizado apenas pesquisas de seu inteiro interesse, sem quase nenhum controle ou imposição acadêmica ou institucional. Isso significava ter tempo e liberdade para se dedicar à pesquisa. A respeito dessa fase, ele salienta: "Minha presente condição é excelente. Eu estou trabalhando duro como jamais trabalhei,

3 A primeira referência à expressão operante apenas ocorre em 1937 no artigo Two Types of Conditioned Reflex: A Reply to Konorski and Miller (Skinner, 1937). Todavia, ainda na primeira da década de 1930, Skinner (1935) já estudava experimentalmente a relação resposta-consequência, que será base para sua posterior diferenciação entre o comportamento operante e respondente. Assim, mesmo que ainda não houvesse formulado essa diferenciação, para o presente caso, não vemos problemas em afirmar que a formulação da noção de operante já estivesse em andamento na primeira metade da década de 1930. mas com tempo disponível e com objeto de estudo de minha própria escolha" (Skinner, 1979, p. 38).

Com o término de sua bolsa de pós-doutorado, em 1935, essa situação favorável é alterada bruscamente. Ter que conseguir um emprego não estava nos seus planos para os próximos trinta anos (Skinner, 1979). Ademais, com a Grande Depressão econômica norte-americana pós-1929, Skinner recorda que os empregos estavam escassos. Portanto, aquela era uma situação nova e desagradável para Skinner, que havia vivido, nos últimos anos, de modo confortável, compartilhando um cotidiano acadêmico motivador e usufruindo de condições excelentes de trabalho (Bjork, 1993). Sobre esse período, que corresponde ao seu pós-doutorado, Skinner afirma que não havia existido melhor oportunidade para se tornar um psicólogo, mas sabia que, naquele momento, "precisava pagar o preço" (Skinner, 1979, p. 178).

$\mathrm{O}$ fato de que não havia escolhido um campo de estudo popular na Psicologia, mas um campo pelo qual se interessava, seria o primeiro empecilho para conseguir um emprego. Outro motivo teria sido sua declarada falta de interesse pela produção daquilo que ele chama de tradicional Psicologia Animal (Skinner, 1979). A respeito disso, Skinner ainda afirma que:

Eu nunca tinha sequer lido um texto inteiro de Psicologia. Até mesmo como um interessado em Psicologia animal eu sabia pouco sobre os erros cometidos pelos ratos em labirintos, ou o número de escolhas feitas na aprendizagem de uma discriminação, ou os processos simbólicos ou insights de primatas - e eu nem tinha qualquer interesse em saber. (Skinner, 1979, p. 179)

Ainda assegura que, apesar de já ter publicado alguns artigos, não havia feito esforços para divulgar seu trabalho. Uma das consequências dessa postura foi que, no próprio departamento de Psicologia em Harvard, ainda durante seu pós-doutorado, Skinner (1979) assegura ter sido tratado como um desertor. Situação que expunha como ele havia se afastado da perspectiva estruturalista que prevalecia no departamento de Psicologia em Harvard ${ }^{4}$. Ao recordar seu "plano de campanha" a ser desenvolvido entre as décadas de 1930 e 1960, uma síntese dos problemas citados é exposta.

No meu "plano de campanha para os anos 30-60", eu não havia mencionado conseguir um emprego. Eu tinha escolhido um campo de pesquisa, não porque era popular, mas porque ele me interessava. Eu não tinha feito nenhum esforço para relacionar o meu trabalho com outros da área, e os outros pesquisadores não tinham nenhuma razão para relatar seus trabalhos para mim. Eu tinha publicado um bom número de artigos, mas eles não estavam na corrente principal da Psicologia americana e quase nunca eram citados. Embora Lashley tivesse dito que gostou do meu artigo sobre o conceito de reflexo, ele nunca se referiu a ele em suas publicações. Hunter me apoiou profissionalmente, mas ele realmente não entendia minha pesquisa. Ninguém estava fazendo um trabalho publicável com meus métodos (Fred

4 Pode-se dizer que Skinner também havia se afastado em alguma medida do próprio behaviorismo norte-americano. Isso porque, ele não recorre a procedimentos e métodos comuns nas pesquisas behavioristas, como grupos controle e médias estatísticas. 
estava apenas começando), e a curva cumulativa ainda era uma curiosidade. (Skinner, 1979, p. 178)

Sobre essa fase, seu colega de doutorado e, posteriormente, o principal disseminador da Análise do Comportamento, Fred. S. Keller (1899 -1996) comenta que tanto ele quanto Skinner estavam em 1935 procurando emprego, mas por diferentes motivos.

Burrhus e eu tínhamos começado a procurar emprego por razões diferentes. Ele estava terminando seu período como bolsista de pós-doutorado em Harvard e, assim, era qualificado demais para trabalhar em muitas instituições educacionais. Eu estava simplesmente procurando encontrar um lugar que me provesse um futuro melhor. Muitas de nossas cartas eram sobre nossa preocupação com abertura de vagas para empregos. (Keller, 2009, p. 155)

Entretanto, Keller (2009) recorda que ficou surpreso ao saber que tinha conseguido emprego antes de Skinner e com melhores condições de trabalho, salário e ascensão acadêmica.

Ao citar duas cartas de Edward G. Boring (1886-1968), enviadas para Skinner nesse período, Bjork (1993) afirma que o então diretor do Departamento de Psicologia de Harvard supôs que a reputação de Skinner estaria amedrontando possíveis empregadores. Isto porque, embora suas formulações ainda não fossem conhecidas, seus cinco anos de pesquisas ininterruptas no pós-doutorado estariam provocando tal efeito. E foi somente após a indicação do próprio Boring, em 1935, que Skinner conseguiu seu primeiro emprego como professor de Psicologia na Universidade de Minnesota.

É no período de trabalho nesta universidade, que corresponde à segunda metade da década de 1930 e início dos anos 1940, que as dificuldades para continuar seu "plano de campanha" tornam-se concretas para Skinner. Isto porque ele assume ser persuadido, durante a segunda metade da década de 30 , a trabalhar em pesquisas que utilizavam teorias e métodos incompatíveis com seu esboço inicial de uma ciência do comportamento. Isso ocorre porque Skinner é contratado para trabalhar com William T. Heron, pesquisador que realizava investigações com grande número de sujeitos experimentais, instrumentos, como labirinto, uso de grupos controle e a utilização de estatística inferencial.

Ao comentar a recepção de seu primeiro livro, The Behavior of Organisms, aspecto que trataremos ainda neste trabalho, e as pesquisas realizadas em Minnesota no final da década de 1930, Skinner (1956) resume algumas das razões que explicam a discrepância entre o que ele havia pesquisado no período anterior em Harvard e o seu trabalho naquele momento com Heron.

A maior parte dos experimentos descritos no livro O Comportamento dos Organismos foi realizado com grupos de quatro ratos. Uma reação bastante comum ao livro foi a de que esses grupos eram muito pequenos. Como eu saberia que outros grupos de quatros ratos fariam a mesma coisa? Keller, ao definir o livro, afirma que grupos de quatro eram na verdade grandes demais. Infelizmente, porém, eu me permiti ser persuadido do contrário, devido, em parte, à minha associação à Universidade de Minnesota com W.T. Heron. Por causa dele, eu entrei em contato próximo pela primeira vez com a tradicional Psicologia Animal. (Skinner, 1956/1961, p. 89)

Dois elementos dessa passagem merecem comentários. O primeiro é que, assumindo que seu comportamento, foi parcialmente controlado pelo contexto institucional e pela presença de um pesquisador que adotava um método diverso daquele utilizado por ele nos anos anteriores, Skinner (1956) expõe como seu comportamento científico naquele contexto fora determinado não pela escolha do modelo que ele já havia formulado e acreditava ser mais efetivo, mas sim pelo controle institucional. Segundo, ao declarar ser a primeira vez que entrava em contato próximo com a tradicional Psicologia Animal, Skinner evidencia que suas formulações anteriores não sofreram influências significativas dessa tradição de pesquisa. Ou seja, Skinner não estava totalmente subordinado ao controle de regras metodológicas derivadas dessa tradição de pesquisa.

Ainda ao descrever sua situação na Universidade de Minnesota, Skinner (1979) evidencia em uma carta enviada para Keller certa satisfação inicial ao trabalhar com Heron. Contudo, alega que, à medida que o tempo passava, sua situação tornava-se cada vez menos confortável, visto que, para ele, a ineficácia do tipo de método utilizado por Heron era evidente. Assim, diz-se preocupado, porque sentia estar cada vez mais longe de realizar pesquisas relacionadas aos seus achados nos anos anteriores em Harvard. Por fim, Skinner expõe que, naquela instituição, não divulgava suas ideias, porque tinha medo de represálias de Heron, que já apresentava sinais de insatisfação em relação ao seu trabalho. Portanto, no final da década de 30 e início dos anos 40, uma posição que lhe permitisse independência acadêmica e institucional parecia bastante difícil. Como ele ressalta:

Eu não via nenhuma maneira rápida de conseguir uma boa posição em Minnesota porque eu tinha meus próprios problemas. Heron estava tornando-se 'descontente e distante'. Eu tinha que evitar falar sobre o meu 'sistema' com alunos de pós-graduação que estavam interessados em trabalhar com animais. (Skinner, 1979, p. 236)

Skinner se refere a esse período como uma época de isolamento acadêmico. A dificuldade e a declarada falta de interesse em estabelecer diálogo com a tradicional Psicologia Animal; a localização geográfica desprivilegiada daquela instituição que, segundo ele, o impedia de manter contato com outros pesquisadores e participar de eventos científicos; e a impossibilidade de divulgar seus achados e de realizar pesquisas fundamentadas no delineamento experimental de sujeito único, sinalizam alguns dos motivos de seu sentimento de isolamento.

Tais problemas enfrentados por Skinner expõem os primeiros percalços envolvidos na aceitação inicial de seu sistema científico. As dificuldades de Skinner em tornar suas formulações aceitas tornam-se ainda mais manifestas quando publica seu primeiro livro: The Behavior of Organisms. Além da recepção negativa, esse livro não provoca o impacto esperado por ele após os primeiros anos de sua publicação. A seguir, são expostos alguns dos motivos dessa recepção e da 
pouca visibilidade dada a essa obra na sua primeira década; também discutiremos como Skinner reagiu a essa situação.

\section{Mais pedras no caminho: a aceitação inicial de The Behavior of Organisms}

Na segunda metade da década de 1930, como exposto,Skinner não mais se dedicou exclusivamente ao desenvolvimento de seu sistema explicativo. Todavia, isso não significou que tenha abandonado seu plano de estabelecer uma nova ciência do comportamento. A tarefa mais importante realizada na segunda metade da década de 1930 em direção ao estabelecimento de sua ciência foi a organização de seu primeiro livro, The Behavior of Organisms: An Experimental Analysis. Livro que apresenta uma síntese de suas pesquisas durante os anos de doutorado e pós-doutorado em Harvard, ou seja, de sua proposta inicial de uma ciência do comportamento. Por isso, Skinner (1979) enfatiza que: "eu não estava propondo apenas uma explicação de minha pesquisa, mas um 'sistema"” (Skinner, 1979, p.201).

Ao se referir à expressão "an Experimental Analysis" no título de seu livro Skinner (1979) argumenta que essa foi uma tentativa inicial de demarcar um novo campo de estudo na Psicologia, campo que se diferenciaria das demais ciências do comportamento por não recorrer ao teste de hipótese e médias estatísticas. A respeito disso ele diz que:

Eu tinha acrescentado "uma análise experimental" ao título do meu livro, e eu comecei a me referir a toda a empreitada como “a Análise Experimental do Comportamento". Isso difere de outros trabalhos sobre Psicologia Animal, principalmente porque eu não tinha médias estatísticas. Eu tinha quatro aparelhos e geralmente publicava resultados de quatro ratos em cada experimento, mas eu considerava cada rato separadamente. (Skinner, 1979, p. 214)

Mesmo que essa obra denote um marco na história da Análise do Comportamento (Catania, 1988, Skinner, 1938, 1979; Todorov, 2008) a aceitação desse livro não se deu de forma automática e sem críticas. Representa, na realidade, as dificuldades de aceitação do delineamento experimental de sujeito único, método que não recorre ao uso do teste de hipóteses e a utilização de grupos controle e que, por essas e outras razões, irá servir de mote para inúmeras críticas que a Análise do Comportamento irá sofrer a partir de então no contexto da Psicologia Experimental norte-americana.

Os primeiros percalços para a aceitação dos resultados divulgados no livro foram expressos nas críticas negativas recebidas logo após a sua publicação em 1938, e revelam o incômodo provocado pela suposta desconsideração de Skinner com os métodos da tradicional Psicologia Animal. O próprio Skinner (1979) lista aquilo que ele julgou serem as críticas mais comuns nas revisões de The Behavior of Organisms. Abaixo, são descritas essas críticas e os comentários de Skinner.

Uma primeira crítica foi a de que o título do livro era pretensioso. Segundo Skinner (1979), essa crítica foi realizada com base na ideia de que experimentos com ratos não eram capazes de prover dados suficientes para um sistema científico do comportamento.

Outra crítica afirma que o livro havia negligenciado inúmeros trabalhos sobre aprendizagem e motivação. Skinner (1979) alega que os críticos o acusaram de não ter usado nenhum conhecimento disponível sobre esses tópicos e de não ter realizado nenhum esforço sério para analisar a enorme literatura existente sobre aprendizagem e condicionamento.

Também foi recorrente a ideia de que não havia nada de novo na afirmação de Skinner de que uma ciência do comportamento não deveria ser sobrecarregada de hipóteses fisiológicas. Skinner (1979) menciona que aqueles que fizeram essa crítica, como Tolman e Hull, não perceberam que, na verdade, em muitos aspectos, suas próprias explicações recorriam a estados fisiológicos e neurológicos como causa do comportamento.

O livro não tratava de temas importantes da Psicologia, tais como percepção e pensamento. Skinner (1979) expõe que esses temas poderiam ser redefinidos operacionalmente a partir de sua explicação do comportamento e fazer parte de seu programa de pesquisa.

Sua alegação de ter abandonado hipóteses era injustificada. Sobre essa acusação, Skinner (1979) argumenta que a única hipótese em seu trabalho era que o comportamento poderia ser explicado como um sistema ordenado.

E, por último, faltava tratamento estatístico dos dados. Para Skinner (1979), seus dados envolvendo sujeitos únicos tinham resultados mais ordenados e reproduzíveis do que os dados de seus contemporâneos, que recorriam a médias estatísticas e a grupos controle.

O que parece ser comum nessas críticas são as afirmações de que aquilo que Skinner estava propondo não se parecia com a tradicional pesquisa em Psicologia Animal. Ademais, refletem a forma pouco expressiva como seu livro havia sido recepcionado até meados da década de 1940 pelos psicólogos experimentais norte-americanos, que mesmo não compartilhando uma matriz disciplinar, supunham que alguns procedimentos - como médias estatísticas, teste de hipóteses e uso de grupos controle - eram métodos comuns e necessários ${ }^{5}$.

Uma das consequências do afastamento da tradicional Psicologia Animal foi que, após os primeiros anos da publicação de The Behavior of Organisms, Skinner não consegue a visibilidade almejada. Ao comentar em encontro, em 1941, com Ernest R. Hilgard (1904-2001), psicólogo experimental da Universidade de Stanford em visita à Universidade de Minnesota, Skinner fala da insatisfação por suas ideias não estarem sendo divulgadas. Além disso, evidencia, mais uma vez, que o seu objetivo não era somente tornar suas pesquisas conhecidas, mas que elas fossem fundamento para a elaboração de uma nova ciência do comportamento.

Quando estávamos andando pelo campus, ele (Hilgard) disse que lamentava que minha pesquisa não fosse ainda bem conheci-

5 É, justamente, a partir da década de 1930, que se inicia uma tendência, a qual será fortalecida até a década de 1960, de definir a estatística inferencial e o uso de grupos controles como procedimentos indispensáveis nas pesquisas em Psicologia Experimental nos Estados Unidos (Winston \& Blais, 1996). Portanto, Skinner propõe um método de pesquisa que estava em desacordo com a hegemonia da Psicologia Experimental estadunidense. 
da e que outros não estavam usando meus métodos. Eu dei a ele a resposta que Crozier havia me dado quando eu reclamei que os psicólogos estavam negligenciando importantes questões: "Por que você deveria se importar. Isso lhe dá mais coisas para fazer." A resposta foi boa o suficiente naquele momento, mas eu já não estava satisfeito com ela. Eu queria ser parte de um campo em expansão. (Skinner, 1979, p. 286)

A inexpressiva vendagem do livro quase uma década após sua publicação é representativa do reconhecimento daquela nova ciência do comportamento em sua primeira década. Sobre isso Skinner (1984) lembra que a edição original de The Behavior of Organisms fora de oitocentas cópias e que, após a Segunda Guerra Mundial, uma nova edição não parecia ser justificada. Também recorda que:

Psicólogos estavam muito ocupados com a guerra para prestar qualquer atenção a experimentos com ratos ou em um livro como O Comportamento dos Organismos - apenas oitenta cópias haviam sido vendidas durante os quatro anos de guerra - e ninguém parecia estar voltado para o estudo do comportamento operante. (Skinner, 1979, p. 285)

Keller foi um dos poucos a recepcionar de maneira positiva o livro. Assim, mesmo já conhecendo as pesquisas de Skinner e utilizando o delineamento experimental de sujeito único, é com a publicação de The Behavior of Organims que Keller expressa seu grande entusiasmo pelo trabalho do amigo. O que é observado em carta enviada para Skinner, em 1938, logo após a leitura do livro:

Isto é a coisa mais excitante que já me roubou o sono tão necessário... Na minha humilde opinião, é a contribuição mais importante que este século viu no campo da Psicologia. Como um belo exemplo de método indutivo e operacionalismo, põe à vergonha Hullianos e Titchnerianos, dentre outros, com suas fortes deduções, suas estreitas aplicações, suas fisiologizações, e seus vagos sonhos de Psicologia como ciência. Inferno! Você sabe o que quero dizer, com toda essa conversa. (Keller, 2009, p. 164)

Além de expressar seu entusiasmo, Keller mostra que havia compreendido que o objetivo de Skinner era a fundação de um novo sistema científico e não o lançamento de um mero livro acerca de algum tópico específico dentro da Psicologia. Neste mesmo momento, como indicado, Skinner (1979) lembra que seu livro estava sofrendo diversas críticas, e assume que ainda não tinha como formular todas as respostas aos problemas postos, "Na verdade, eu dava pouca atenção aos meus críticos. Mas eu estava contente de ser reconfortado por Fred que disse que: 'Agora estou definitivamente na onda Skinner" (Skinner, 1979, p. 233). O entusiasmo de Keller parece ter sido tanto, que Skinner em entrevista concedida a um de seus biográficos, afirma que Keller tinha mais fé no seu livro do que ele (Bjork, 1993).

Ademais, Keller irá desempenhar papel especial na institucionalização da disciplina. A elaboração e a implantação do primeiro currículo de Análise Experimental do Comportamento em conjunto com William N. Schoenfeld (1915-1996) (Keller \& Schoenfeld, 1949); a publicação do primeiro livro texto de Análise Experimental do Comportamento, também em coautoria Schoenfeld (Keller \& Schoenfeld, 1950); e a difusão da área em vários países são representativas do papel de porta-voz da Análise do Comportamento assumido por Keller durante toda sua carreira (Keller, 2009; 1975; Matos; 1996; Miranda \& Cirino, 2010).

Embora Skinner afirme que não havia prestado muita atenção aos seus críticos, isso não significa que ele deixou de se importar com as opiniões acerca de seu livro. O que é percebido quando relata como alguns psicólogos o recepcionaram. Neste contexto, Clark L. Hull (1884-1952) e Edward C. Tolman (1886-1959) são os alvos das reivindicações de Skinner por reconhecimento. Uma análise de como ele lidou com a posição desses dois eminentes psicólogos experimentais norte-americanos, após a publicação de seu livro, será descrita a seguir, e denota como sua ciência do comportamento estava inserida em um campo de disputa com outras teorias do comportamento ${ }^{6}$.

\section{Skinner, Tolman e Hull: as disputas pelo estabelecimento de uma ciência do comportamento}

A escolha de Hull e Tolman por parte de Skinner para representar como seu sistema científico havia sido recepcionado e estava num campo de disputa difícil não ocorreu por acaso. Hull e Tolman estavam entre os mais conceituados psicólogos norte-americanos da primeira metade do século $\mathrm{XX}$ e haviam, igualmente, publicado livros que se tornariam marcos na história da Psicologia Experimental. Por isso, para Skinner (1988), uma análise histórica de seu livro não poderia deixar de levar em conta os trabalhos de Tolman e Hull. Deste modo:

Duas outras análises teóricas experimentais do comportamento constituem o contexto histórico em que este livro deve ser avaliado. Comportamento Intencional em Animais e Homens precedeu O Comportamento dos Organismos em seis anos; Principios do Comportamento de Hull foi publicado cinco anos depois. Os três livros diferem em muitas maneiras: eles se comprometem a resolver diferentes problemas e eles buscaram soluções em diferentes lugares. (Skinner, 1988, p. 355)

Os comentários de Skinner sobre a recepção de Hull e Tolman acerca de seu livro não se referem às possíveis críticas negativas, mas, em particular, à falta ou ao pouco reconhecimento público e a não utilização dos seus achados pelos dois psicólogos.

O primeiro alvo de suas reivindicações por reconhecimento foi Hull. Em uma carta enviada a Keller, Skinner se diz insatisfeito perante a falta de comentários de Hull sobre seu livro que, segundo Skinner (1979), utilizava seu método. "Hull ainda não quebrou seu completo silêncio sobre o livro (O Comportamento dos Organismos) e sobre seu próprio trabalho com o método" (Skinner , 1979, p. 269). Skinner

6 Enfatizamos, no presente trabalho, como Hull e Tolman recepcionaram o livro de Skinner. Não foi nosso objetivo discutir as diferenças de posições teóricas entre esses autores. Para essa discussão, ver Abib (1997), Laurenti (2008) e Lopes (2008). 
(1979) ainda diz que muitos dos experimentos apresentados por Hull foram realizados com "Caixas de Skinner", mas não havia quase nenhuma referência a seu livro. Na realidade, segundo Skinner, "Hull tendeu a passar por cima do meu trabalho" (Skinner, 1979, p.269-270).

A falta de pronunciamento de Hull sobre o livro, não significou, no entanto, sua total desconsideração do trabalho de Skinner. Bjork (1993) lembra que Hull escreveu para Skinner, ainda em 1934, dizendo que estava acompanhando as suas pesquisas com interesse. O próprio Skinner (1979) recorda que Hull expressou simpatia pela sua proposta de uma ciência do comportamento ainda em 1933, e lembra que, após sua apresentação no encontro da Associação Americana para o Avanço da Ciência (AAAS), naquele ano, "ele (Hull) se levantou e disse que queria chamar a atenção do público para o trabalho desse jovem homem" (Skinner, 1979, 204). Uma semana após esse episódio, Hull enviou-lhe uma carta relatando o interesse pelo seu trabalho e solicitando-lhe o envio de uma cópia da apresentação. Nessa mesma carta, Hull convida Skinner para apresentar um seminário em seu laboratório, na Universidade de Yale. Esse foi apenas o primeiro contato de muitos outros que ocorreram ao longo das duas próximas décadas (Skinner, 1979).

De qualquer forma, a insatisfação de Skinner parece ser legítima quando se refere ao não reconhecimento de Hull acerca do uso da caixa de condicionamento inventada por ele. No entanto, necessita ser atenuada quando se refere à utilização de seu método por parte de Hull. Isso porque, mesmo que Hull tenha recorrido à "pressão barra" e ao "registro cumulativo", ele não trabalhou com o delineamento experimental de sujeito único nem utilizou uma explicação operante do comportamento. Além disso, fez adaptações no aparato, utilizando, por exemplo, duas barras de pressão ao invés de uma. Hull, portanto, utilizou o instrumento inventado por Skinner, mas recorreu a outra explicação do comportamento para analisar os resultados de suas pesquisas.

O próprio Skinner (1979) ameniza suas críticas a Hull, e diz que esse não estava deliberadamente desconsiderando suas formulações. Na verdade, Hull era, até então, o único psicólogo, salvo Keller, que havia demonstrado algum interesse e mantinha estudantes trabalhando com algo similar às pesquisas de Skinner. Não é por acaso que foram Hull e seus alunos os responsáveis por denominar a caixa de condicionamento operante de "Caixa de Skinner" (Skinner, 1938/1966). Além disso, Skinner reconhece que não podia reclamar nem esperar muito de Hull.

Eu raramente reclamei, porque eu mesmo nunca fiz qualquer uso do trabalho de Hull ou de seus estudantes, particularmente de Kenneth Spence ou Neal Miller. Meus resultados não se encaixavam em suas teorias nem os seus resultados em minhas formulações. (Skinner, 1979, p. 270)

Ao contrário de Hull, Tolman pronunciou-se sobre o sistema científico que se apresenta no livro de Skinner. Em carta enviada para Ferrin, editor da Appleton-Century-Crofts, responsável pela publicação do primeiro livro tanto de Tolman, quanto de Skinner e Hull, ele relata sua opinião sobre The Behavior of Organisms. Nesta correspondência, diz que:
O Comportamento dos Organismos. Eu o considero um livro marcante, tanto por causa dos resultados experimentais muito importantes e por causa do claro e, a meu ver, extremamente significativo "sistema" que se apresenta como arcabouço para esses resultados. Ele sempre terá um lugar muito importante na história da Psicologia. (Carta de Tolman enviada para Ferrin, 1938, citada por Skinner, 1979, p. 221)

Skinner também recebe de Tolman uma carta com comentários sobre o livro. Nessa, Tolman diz que:

Há muito tempo eu não ficava tão animado intelectualmente como agora quando estou folheando o seu livro. É, naturalmente, uma contribuição muito importante para a "real" Psicologia... Acho que as duas palavras, operante e respondente, são excelentes. Sua análise das funções do estímulo é também extremamente importante e todo o trabalho esclarece muitas das questões que sempre me preocuparam... Quero parabenizá-lo por sua passagem por Harvard tão belamente ileso!

P.S. E claro que eu fiquei satisfeito como nunca por ter sido mencionado no Prefácio. (Tolman, 1938)

Embora Tolman tenha informalmente elogiado o trabalho de Skinner, isso não foi suficiente para que ele utilizasse as formulações teóricas e metodológicas apresentadas naquele livro. Tolman, assim como Hull, conserva inalterado seu interesse pela perspectiva em que estava trabalhando.

Sobre o fato de Hull não comentar o trabalho de Skinner e Tolman, por sua vez, comentá-lo positivamente, mas não utilizar suas formulações, Skinner (1979) sugere que "Não foi, creio eu, um isolamento autocentrado por parte de ninguém, a ciência ainda não tinha encontrado uma formulação geral aceita" (p. 270). Pensamento esse que revela a crença compartilhada, naquele período por vários psicólogos norte-americanos, de que a história da Psicologia chegaria a um estágio no qual uma formulação geral seria aceita por toda a comunidade científica. Um dos maiores exemplos da busca pelo estabelecimento de um abrangente sistema científico no campo psicológico foi o livro de Hull, Principles of behavior: An Introduction To Behavior Theory, de 1943. Bjork (1993), ao comentar a busca de Hull pela fundação de um sistema científico geral na Psicologia, alega que a crença de Hull na construção de uma ciência nesses moldes era tal, que:

...ele recomendou que, para 'o bem de sua alma', Skinner deveria ler Principia Mathematica de Isaac Newton. Hull acreditava que não havia problema insuperável na aplicação dos fundamentos teóricos de uma ciência para outra, e acreditava que ele poderia ser o Newton da ciência comportamental. (Bjork, 1993, p. 111)

Ainda sobre o desejo de Hull em elaborar um sistema geral do comportamento, "Hull tornou-se um defensor entusiasta do postulado do método formal. Ele estudou cuidadosamente o principal livro de Newton, Principia e se esforçou para usá-lo como seu modelo..." (Spence, 1966, p. xvi).

O principal livro de Tolman, Purposive Behavior in Animals and Men, de 1932, embora não siga a mesma perspectiva de Hull, apresenta-se também como proposta de fundação de um sistema explicativo geral do comportamento. Krech 
(1967), ao comentar o papel histórico dessa obra, diz que esse livro "representa um dos grandes sistemas da Era dos Construtores de Sistema na Psicologia americana" (p. xi). Livros, como o próprio The Behavior of Organisms, de Skinner, e o trabalho de Keller \& Schoenfeld, Principles of Psychology: A Systematic Text in the Science of Behavior, de 1950, este baseado em uma explicação operante do comportamento e organizado com o objetivo de ser o primeiro livro-texto de Psicologia fundamentado nesta ciência, são apenas alguns dos exemplos que retratam as inúmeras tentativas de estabelecimento de grandes sistemas explicativos na história da Psicologia entre a segunda metade do século XIX e durante grande parte do século XX.

Portanto, o reconhecimento e a adoção de formulações de outros psicólogos por parte de Hull, Tolman e Skinner seria algo que diminuiria as chances de reconhecimento dos seus próprios trabalhos. A ausência de referências ou apenas elogios pontuais, como foram os casos, respectivamente, de Hull e Tolman acerca do sistema explicativo skinneriano, seria mais um reflexo da situação da Psicologia Experimental norte-americana daquela época, em que diversos psicólogos buscavam estabelecer suas teorias como dominantes, do que a total desconsideração pela obra de Skinner. O que é manifesto quando o próprio Skinner (1984) afirma que "Os melhores exemplos de teóricos que eu estava atacando era Clark L. Hull e Edward C. Tolman"' (p. 12). Ainda sobre essa situação, Bjork (1993) afirma que, mesmo que Hull e Tolman estivessem impressionados com a proposta de Skinner, nunca abandonaram suas perspectivas pela abordagem skinneriana que era, dentre outras coisas, mais integralmente descritiva e menos dedutiva do que a desses dois psicólogos.

\section{O início da aceitação da Análise Experimental do Comportamento e a coexistência com outras explicações do comportamento}

É após a Segunda Guerra Mundial que se inicia uma transição no Behaviorismo americano. A partir desse momento, Skinner tem sua ciência adotada por uma comunidade científica em formação. Isso denotou, para alguns intérpretes da história da Psicologia norte-americana, que à medida que as ideias de Skinner tornavam-se conhecidas e aceitas, as de Hull e Tolman tornavam-se menos reconhecidas e aceitas. Bjork (1993), por exemplo, irá alegar que:

Com o país enfrentando a Grande Depressão, B.F. Skinner trabalhava em relativa obscuridade, em comparação com Clark L. Hull de Yale e Edward Chace Tolman da Universidade da Califórnia. Hull estava empenhado em descobrir equivalentes matemáticos para leis do comportamento, enquanto Tolman analisava o "comportamento intencional". Além disso, ambos eram professores com leais estudantes de pós-graduação e apoiados por colegas behavioristas. Na década seguinte, Skinner reuniria um programa experimental que condenaria Tolman e Hull à relativa obscuridade, enquanto a sua estrela profissional brilhava. (Bjork, 1993, p. 105).

Mesmo sendo evidente, na história da Psicologia norte-americana, a emergência de uma comunidade científica fundamentada nos princípios da teoria operante a partir de meados da década de 1940, a afirmação de Bjork (1993) de uma suposta supremacia do pensamento de Skinner deve ser mitigada. Isso porque, dificilmente, a aceitação e disseminação das ideias de Skinner aconteceram em função da substituição ou abandono dos sistemas científicos de Hull e Tolman. Em outras palavras, é precipitado afirmar que ocorreu o abandono total desses autores e uma adesão maciça às proposições skinnerianas. Hull e Tolman não deixaram de ser reconhecidos como relevantes influências no desenvolvimento de teorias e campos de investigações internos e externos à Psicologia.

A respeito de Hull, por exemplo, é dito que seu principal livro, Principles of Behavior, entre as décadas de 1940 e 1950, "marcou o início de uma era na pesquisa psicológica em que Hull tornou-se inquestionavelmente o líder da pesquisa em aprendizagem no país...” (Marx \& Hillix, 1963, p. 244). Ademais, formulações atuais identificam o trabalho de Hull como parte constituinte da história da Inteligência Artificial e de outros campos de pesquisa, como a Cibernética, que ganharam força na segunda metade do século XX (Schlimm, 2009).

Sobre Tolman, o próprio Skinner (1988) sugere que esse teria sido um dos precursores da moderna Psicologia Cognitiva que surge nas décadas de 1950 e 1960, e Chiesa (1994) irá afirmar que "como um psicólogo tentando desenvolver métodos mais alinhados com as ciências naturais, Tolman pertence à tradição 'comportamental'. Já no contexto da Psicologia Contemporânea, sua abordagem S-O-R é seguramente cognitiva" (p. 193). Krech (1967) alega que, embora a obra de Tolman parecesse esquecida nas décadas de 1950 e 1960, sua relevância é explícita em diversos estudos desse período, que revisitam conceitos como de "mapas cognitivos", "expectativas" e "hipóteses", todos presentes na obra de Tolman. Carrara (2005) também irá argumentar que Tolmam, mesmo que de forma indireta, contribuiu com a Cibernética, que incorporou a ideia de intenção presente em seu sistema explicativo como um fenômeno que poderia ser operacionalmente definido.

No prefácio da sétima edição de Principles of Behavior de Hull publicada em 1966 as obras de Hull, Tolman e Skinner são citadas por desempenharem papel central no desenvolvimento da Psicologia Experimental norte-americana. Sobre isso é dito que:

Em curto espaço de tempo, nos últimos 11 anos apareceram, na Century Psychology Series, três livros que não apenas decisivamente determinaram o curso que uma área da Psicologia estava tomando nos 20 anos seguintes, mas também literalmente instigou a maioria das pesquisas na mesma. Os livros, por ordem de seus lançamentos, foram Comportamento Intencional em Animais e Homens (1932) de Tolman, O Comportamento dos Organismos (1938) de Skinner e Princípios do Comportamento (1943) de Hull. (Spence, 1966, p. xvi).

Essa afirmação evidencia que não fora mera presunção de Skinner situar seu livro historicamente em referência aos livros de Hull e Tolman. Todavia, observa-se que o número de edições dos livros de Skinner e Hull indicam uma maior difusão de suas formulações em comparação com Tolman 
(Gengerelli, 1976; Marx \& Hillix, 1963). Com a diferença de que as formulações skinnerianas serão difundidas e aplicadas por um visível grupo de praticantes de sua ciência a partir da década de 1950. Fenômeno esse que não ocorrerá de forma evidente com as formulações de Hull e Tolman.

Dessa maneira, embora Hull e Tolman não sustentem tão claramente uma comunidade científica baseada em suas formulações, algo que ocorrerá de forma mais evidente com as ideias de Skinner a partir de meados da década 1940, não se pode afirmar que houve desaparecimento, substituição ou total desuso dos achados de Hull e Tolman, como se o Behaviorismo skinneriano tivesse assumido a posição de domínio na Psicologia Experimental norte-americana.

O que se observa é que a inserção da Análise Experimental do Comportamento em currículos de cursos de Psicologia (Keller \& Schoenfeld, 1949); a fundação da primeira sociedade científica da área (Dinsmoor, 1987; Laties, 1987); o estabelecimento de revistas especializadas (Catania, 2008; Schoenfeld, 1987; Skinner, 1987; Wixted, 2008); e de programas de doutorado e mestrado (Michael, 1993; Rubin \& Cuvo, 1993) e a aplicação dos princípios da teoria operante em diversos contextos (Rutherford, 2009); denotam a formação de uma nova comunidade científica entre as décadas de 1940 e 1950 nos Estados Unidos. O que permite concluir, como sugere Kuhn (1962/2006):

A criação de publicações especializadas, a fundação de sociedades de especialistas e a reivindicação de um lugar especial nos currículos de estudo têm geralmente estado associadas ao momento em que um grupo aceita pela primeira vez um paradigma único. Pelo menos foi isso que ocorreu, há um século e meio atrás, durante o período que vai desde o desenvolvimento de um padrão institucional de especialização científica até a época recente, quando a parafernália de especializações adquiriu prestígio próprio. (Kuhn, 1962/2006, p. 40)

Portanto, mesmo sem defender e supor a ideia de que houve o estabelecimento de um novo paradigma científico nesse contexto ${ }^{7}$, a organização comunitária da Análise Experimental do Comportamento reflete um padrão histórico do desenvolvimento da ciência quando do surgimento de novas comunidades científicas fundamentadas em uma matriz disciplinar.

\section{Considerações finais}

Os primeiros percalços envolvidos no estabelecimento do sistema explicativo skinneriano envolveram fatores além daqueles descritos na literatura tradicional da história da ciência. Questões de ordem profissional, institucional, econômica, motivacional e de disputas com outros psicólogos

7 Embora tenha se tornado recorrente o uso da noção kuhniana de ciência paradigmática entre psicólogos (Carone, 2003; Coleman \& Rebeca, 1988), essa categoria foi descrita por Kuhn (1962/2006) como incapaz de ser utilizada para se referir a ciências como a Psicologia. Todavia, posteriormente, ele irá argumentar que alguns campos, como a Psicologia Experimental e a Economia, pudessem funcionar segundo sua ideia de ciência normal mesmo não existindo paradigmas nessas ciências (Kuhn, 2006). e suas teorias do comportamento foram assim identificadas como parte da história da formação inicial da Análise do Comportamento. O que nos leva a concluir que os aspectos tratados nesta investigação não podem ser vistos como meros panos de fundo do debate científico. Ou seja, a história de uma ciência sempre abarca mais do que os debates em torno do seu conteúdo científico.

No caso da história inicial da Análise Experimental do Comportamento, as dificuldades enfrentadas por Skinner para continuar seu trabalho em função das mudanças de condições institucionais em meados da década de 1930 se constitui como o primeiro obstáculo para que ele continuasse o trabalho de desenvolvimento de seu sistema científico. Além disso, mostra como condições concretas de trabalho e de relações institucionais influenciaram Skinner e o desenvolvimento de seu plano de constituição de uma ciência do comportamento.

O segundo percalço abarcou a própria recepção de suas ideias no contexto da Psicologia Experimental norte-americana. A recepção negativa de seu primeiro livro, The Behavior of Organisms, e as críticas, em especial, ao seu método de pesquisa, revelam como a proposta de Skinner de uma ciência experimental do comportamento baseada em um novo tipo de experimentação soou como estranha naquele contexto. Em outras palavras, incompatível com a tradição experimentalista norte-americana que naquele momento adere de forma maciça a métodos estatísticos e ao uso de grupos controle como procedimentos indispensáveis na pesquisa experimental em Psicologia.

A disputa com outros psicólogos experimentais que também buscavam estabelecer seus sistemas científicos como dominantes na Psicologia Experimental norte-americana foi o terceiro percalço. Neste cenário, Hull e Tolman são citados por Skinner como seus principais adversários na busca pelo estabelecimento de uma formulação geral sobre o comportamento. E, mesmo que Skinner pareça ter se sobressaído em alguma medida nessa disputa, isso não significou que suas formulações foram aceitas por toda a comunidade científica, nem que as ideias de Hull e Tolman foram abandonadas. Embora não tratemos de maneira detalhada essa questão no presente trabalho, o mais provável é que, como sugerido, a organização comunitária da Análise do Comportamento, a partir de meados da década de 1940 e durante as décadas de 1950 e 1960, tenha se estabelecido de maneira consistente, sustentada por uma forte organização social da ciência, aos moldes de uma ciência normal (Kuhn, 1962/2006). Diferente disso, Hull e Tolman tiveram suas formulações reelaboradas e adaptadas por diversas abordagens. E, não há indícios de uma comunidade científica que tenha se formado e permanecido ativa na história da Psicologia norte-americana baseada estritamente nos sistemas explicativos desses psicólogos. Todavia, vale lembrar que a sobrevivência e a grande expansão da Psicologia Cognitiva e das neurociências a partir da segunda metade do século XX sugerem que a influência do pensamento de Hull e Tolman seja maior em alguns campos do conhecimento, do que as proposições skinnerianas que ainda continuam, grandemente, aceitas apenas entre os membros da comunidade comportamentalista (Krantz, 1971, 1972; Rutherford, 2009). 
Por fim, a presente interpretação aponta que a visão de harmonia na história da ciência representada pela ideia de que a formulação de um fato científico garantiria a um cientista e sua teoria lugar especial na história da ciência é dissolvida quando olhamos para os percalços envolvidos no caminho de sua aceitação. Nesse caso, observamos que a formulação de uma nova ciência do comportamento formulada por Skinner não foi automaticamente aceita e adotada; e que os motivos para tanto envolveram determinantes de natureza social que precisam ser inseridos como elementos necessários para compreensão do seu posterior desenvolvimento.

\section{Referências}

Abib, J. A. D. (1997). Teorias do comportamento e subjetividade na psicologia. São Carlos: Editora da Universidade Federal de São Carlos.

Bjork, D. W. (1993). B.F. Skinner: A life. New York: Sheridan Books.

Carone, I. (2003). A Psicologia tem paradigma? São Paulo: Casa do Psicólogo: FAPESP.

Carrara, K. (2005). Behaviorismo radical: Crítica e metacrítica, ( $2^{\mathrm{a}}$ ed.). São Paulo: Editora Unesp.

Catania, A. C. (1988). The behavior of organisms as work in progress. Journal of the Experimental Analysis of Behavior, 50 (2), 277-281.

Catania, A. C. (2008). The Journal of the Experimental Analysis of Behavior at zero, fifty and one hundred. Journal of the Experimental Analysis of Behavior, 89 (1), 111-118.

Chiesa, M. (1994). Radical Behaviorism: The philosophy and the science. Boston: Authors Cooperative.

Coleman, S. R., \& Rebeca, S. (1988). Kuhn's structure of scientific revolutions in the psychological journal literature, 1969-1983: a Descriptive study. The Journal of Mind and Behavior, 4, 415-446.

Dinsmoor, J. A. (1987). A visit to Bloomington: The first conference on the experimental analysis of behavior. Journal of the Experimental Analysis of Behavior, 48 (3), 441-445.

Fleck, L. (1979). Genesis and development of a scientific fact (F. Bradley, \& T. J. Trenn, Trans., 2a ed). Chicago: University of Chicago Press. (Trabalho original publicado em 1935)

Gengerelli, J. A. (1976). Graduate school reminiscences: Hull and Kofka. American Psychologist, 31(10), 685-688.

Hull, C. L. (1966). Principles of behavior: An introduction to behavior theory. New York: Appleton-Century-Crofts. (Trabalho original publicada em 1943)

Keller, F. S. (1975). On my experience in Brazil. Boletim de Psicologia, 26 (69), 105-110.

Keller, F. S. (2009). At my own pace: The autobiography of Fred S. Keller. New York: Sloan Publishing.

Keller, F. S., \& Schoenfeld, W. N. (1949). The psychology curriculum at Columbia College. American Psychologist, 4 (2), 165-172.

Keller, F. S., \& Schoenfeld, W. N. (1950). Principles of psychology: A systematic text in the science of behavior. New York: Appleton-Century-Crofts.

Krantz, D. L. (1971). The separate worlds of operant and nonoperant psychology. Journal of Applied Behavioral Analysis, 4, 61-70.
Krantz, D. L. (1972). Schools and systems: The mutual isolation of operant and non-operant psychology as a case study. Journal of the History of the Behavioral Sciences, 8, 86-102.

Krech, D. (1967). Editorial: Purposive behavior in animals and men. New York: The Century. (Trabalho Original publicado em 1932)

Kuhn, T. S. (2006). A estrutura das revoluções cientificas (B. V. Boeira \& N. Boeira, Trads., 9a ed.). São Paulo: Perspectiva. (Trabalho original publicado em 1962)

Kuhn, T. S. (2006). O Caminho desde a Estrutura. São Paulo: SP. Editora UNESP.

Laties, V. G. (1987). Society for the experimental analysis of behavior: The first thirty years $(1957-1987)$. Journal of the Experimental Analysis of Behavior, 48 (3), 495-512.

Laurenti, C. (2008). O materialismo-com-mente de Clark Hull (1884-1952). In W. C. M. P. S. (Ed.), Sobre comportamento e cognição: Vol.2 (pp. 35-44). Santo André: ESETec.

Lopes, C. E. (2008) Uma matriz de influências como instrumento de análise da obra de E. C. Tolman. Psicologia em Pesquisa, 2 (2), 14-22.

Marx, M. H., \& Hillix, W. A. (1963). Systems and theories in psychology. New York: McGraw-Hill.

Matos, M. A. (1996). Contingências para a análise comportamental no Brasil. Psicologia: Teoria e Pesquisa, 12 (2), 107-111.

Michael, J. (1993). A brief overview of the history of Western Michigan University's behavioral programs. Journal of Applied Behavior Analysis, 26 (4), 587-588.

Miranda, R. L., \& Cirino, S. D. (2010). Os primeiros anos dos laboratórios de análise do comportamento no Brasil. Psychologia Latina, 1 (1), 79-87.

Rubin, H. B., \& Cuvo, A. J. (1993). The behavior analysis and therapy program at Southern Illinois University at Carbondale. Journal of Applied Behavior Analysis, 26 (4), 583-586.

Rutherford, A. (2009). Beyond the box: BF Skinner's technology of behavior from laboratory to life, 1950s-1970s. University of Toronto Press.

Schlimm, D. (2009). Learning from the existence of models. On psychic machines, tortoises, and computer simulations. Synthese, 169 (3), 521-538.

Schoenfeld, W. N. (1987). Reminiscences, you say? Journal of the Experimental Analysis of Behavior, 48 (3), 464-468.

Skinner, B. F. (1935). The generic nature of the concepts of stimulus and response. Journal of General Psychology, 12, 40-65.

Skinner, B. F. (1937). Two types of conditioned reflex: A reply to Konorski and Miller. Journal of General Psychology, 14, 279-295.

Skinner, B. F. (1966). The behavior of organisms: An experimental analysis. New York: Appleton-Century. (Trabalho original publicado em 1938).

Skinner, B. F. (1956). A case history in scientific method. The American Psychologist, 11 (5), 221-233.

Skinner, B. F. (1979). The shapping of a behaviorist. New York, Alfred A. Konpf.

Skinner, B. F. (1984). A matter of consequences. New York University Press.

Skinner, B. F. (1987). Antecedents. Journal of the Experimental Analysis of Behavior, 48 (4), 447-493.

Skinner, B. F. (1988). Preface to The Behavior of Organisms. Journal of the Experimental Analysis of Behavior, 50 (2), 355-358. 
Spence, K. (1966). Editorial. Hull, C. L. (1966). Principles of behavior: An introduction to behavior theory. New York: Appleton-Century-Crofts. (Trabalho original publicado em 1943).

Todorov, J. C. (2008). Uma revisão de revisões por ocasião dos 70 anos de O Comportamento dos Organismos de B. F. Skinner. Revista Brasileira de Análise do Comportamento, 4 (1), 1-7.

Tolman, E. C. (1967). Purposive behavior in animals and men. New York: The Century. (Trabalho original publicado em 1932)

Tolman, E. C. (1938, November, 14). Unpublished letter to B. F. Skinner. Harvard University Archives, Cambridge, MA.

Winston, A. S., \& Blais, D. J. (1996). What counts as an experiment?: A transdisciplinary analysis of textbooks, 1930-1970. American Journal of Psychology, 109, 599-616.
Wixted, J. (2008). JEAB and the Skinnerian interpretation of behavior. Journal of the Experimental Analysis of Behavior, 89 (1), 137-139.

\section{Congresso Brasileiro de Psiquiatria \\ "Acesso a Tratamento e Justiça Social"}

Recebido em 08.10.2009

Primeira decisão editorial em 04.06.2011

Versão final em 04.07.2011

Aceito em 05.07.2011

05 de Novembro de 2011

Rio de Janeiro, RJ, BR 